\title{
The Metatarsal Axis Deviation Angle: A Novel Angular Measurement for Planning Surgery of Severe Hallux Valgus
}

\author{
Avadhoot P Kantak
}

\begin{abstract}
Surgical planning for hallux valgus is a complex procedure. Many angular measurements are described to decide on the correct procedure. Primus metatarsus varus is considered as one of the important factors in the causation and persistence of hallux valgus. Intermetatarsal angle (IMA) has been used to assess the first metatarsal varus. However, we identified a normal IMA in some feet with severe hallux valgus; and these feet had metatarsus adductus. Hence, after further investigations, we propose a new angular measurement to detect axis deviation of the first metatarsal. We have called this the metatarsal axis deviation angle (MADA). We also recommend a basal realignment osteotomy in hallux valgus with the MADA of more than $30^{\circ}$.
\end{abstract}

Keywords: Hallux valgus, Primus metatarsus varus, Surgery.

How to cite this article: Kantak AP. The Metatarsal Axis Deviation Angle: A Novel Angular Measurement for Planning Surgery of Severe Hallux Valgus. J Foot Ankle Surg (AsiaPacific) 2017;4(2):97-99.

Source of support: Nil

Conflict of interest: None

\section{INTRODUCTION}

Hallux valgus is a common condition, and surgical correction has remained a challenge over the last 100 years with at least 130 procedures being described. ${ }^{1}$ The choice of operation depends principally on the severity of the deformity. ${ }^{2,3}$ For mild and moderate deformities, distal osteotomies of the first metatarsal joint, such as the Chevron, Austin, Wilson, or Mitchell techniques are used. ${ }^{4}$ A proximal metatarsal osteotomy is recommended for more severe deformities because it allows for a greater degree of correction. ${ }^{3}$ This may be at the expense of stability and bony healing. The Scarf osteotomy has gained popularity because of its inherent stability, minimal shortening of the first metatarsal, and ease of internal fixation. ${ }^{5}$

\section{Consultant}

Department of Orthopaedics, East Surrey Hospital, Horley Surrey, UK

Corresponding Author: Avadhoot P Kantak, Consultant Department of Orthopaedics, East Surrey Hospital, Horley Surrey, UK, Phone: +1293277678, e-mail: dravadhoot@yahoo. co.uk
However, these procedures result in a $10 \%$ recurrence rate. ${ }^{6}$ Radiographic and clinical parameters like hallux valgus angle (HVA), intermetatarsal angle (IMA), distal metatarsal articular angle (DMAA), and tarsometatarsal (TMT) hypermobility have been developed to identify different types of hallux valgus. Severity of each parameter is based on cut-off points and used in algorithms to choose between different surgical procedures. ${ }^{7,8}$ Radiographic cut-off points lie between 20 and $40^{\circ}$ for HVA, 11 to $20^{\circ}$ for IMA, and 10 to $15^{\circ}$ for DMAA. Evidence for algorithms is derived from few retrospective studies. ${ }^{9}$ Outcomes of other studies do not support the validity of individual features, such as TMT hypermobility, IMA, and DMAA. ${ }^{10}$ Randomized controlled trials show no difference in correction between Lapidus and distal osteotomy nor shaft and distal osteotomy. ${ }^{10,11}$

The angle between the first and second metatarsals has long been considered an important factor in the development of hallux valgus. Truslow ${ }^{12}$ believed that the increased IMA which he labeled metatarsus primus varus was congenital, and that it inevitably resulted in hallux valgus. In their statistical survey of normal and hallux valgus feet, Hardy and Clapham ${ }^{13}$ found that the most consistent correlation in all their data was the association between the severity of hallux valgus and the magnitude of the IMA. Lundberg and Sulja ${ }^{14}$ found a similar correlation, but were cautious about interpreting the relationship in etiological terms. Piggot, ${ }^{15}$ however, contradicted the widely held belief that metatarsus primus varus was the underlying cause of hallux valgus, noting that some cases of hallux valgus had normal IMAs.

We believe that a normal IMA does not rule out primus metatarsus varus and our novel measurement could address this conundrum.

\section{OBJECTIVE}

As discussed, IMA is considered as an important determinant of hallux valgus severity. But we observed that in feet with an element of metatarsus adductus, the IMA was not as effective. A normal IMA could be present in a patient despite first metatarsal varus, due to varus in the entire forefoot (Fig. 1). This confuses the surgical 


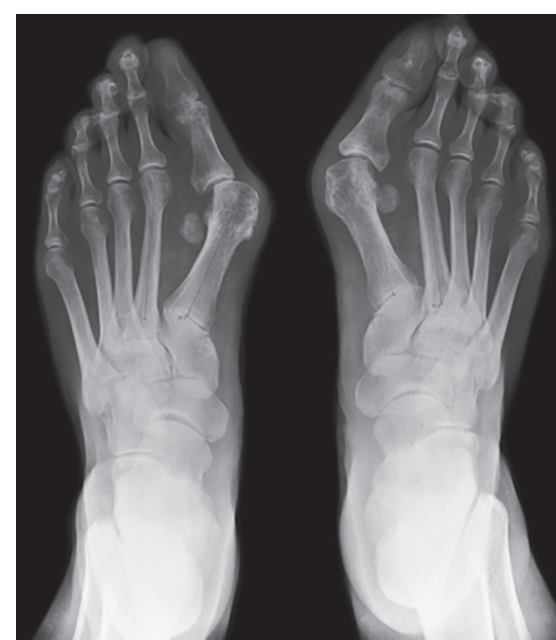

Fig. 1: Metatarsus adductus with slightly increased IMA (IMA $13.5^{\circ}$, MADA $47^{\circ}, \mathrm{HVA} 35^{\circ}$ )

planning process and there is a risk of poorer outcomes. We introduced a new angle to quantify a combined effect of primus metatarsus varus and metatarsus adductus. We have termed this metatarsal axis deviation angle (MADA) (Fig. 2). We hypothesized that this angle correlated better with the severity of hallux valgus. Our research aimed to compare the correlation between IMA and MADA on the severity of hallux valgus.

\section{MATERIALS AND METHODS}

58 dorsoplantar feet radiographs were retrospectively evaluated. The cohort included 38 women and 20 men with symptomatic moderate-to-severe hallux valgus. The severity was classified on the basis of HVA. Patients with HVA of more than $25^{\circ}$ were included. Exclusion criteria were previous forefoot surgery and any congenital foot deformities requiring treatment. The average age was 35.36 (19-71). The radiographic measurements were made on the picture archiving and communication system . The HVA was calculated between the axis of first metatarsal and the proximal phalyngeal axis. The IMA was the angle between the first and second metatarsals. The metatarsus adductus angle (MAA) was calculated by the Engel et a ${ }^{16}$ method, as the angle between the axis of second metatarsal and the axis of middle cuneiform. The MADA was calculated as the angle between the axis of first metatarsal and the axis of middle cuneiform. The average HVA was $35.52^{\circ}$. The average IMA was $14.38^{\circ}$. The average metatarsus adductus (MA) angle was $25.87^{\circ}$. The average MADA was $39.83^{\circ}$.

\section{Statistical Analysis}

We analyzed the data using online statistical software (Statistical Package for the Social Sciences). We identified and compared the association of both the IMA and

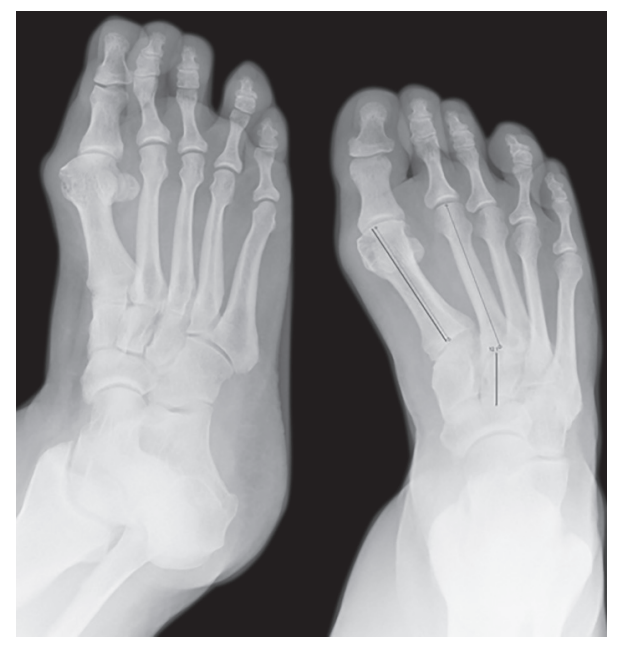

Fig. 2: Normal IMA, but significant first metatarsal varus and severe hallux valgus (IMA $12^{\circ}, \operatorname{MADA} 45^{\circ}, \operatorname{HVA} 32^{\circ}$ )

MADA with the HVA. We also compared the association between the IMA and the MAA. Pearson correlation coefficient was utilized for this purpose.

\section{RESULTS}

The association between IMA and the HVA was weakly positive $(r=0.4754)$. The association between the MADA and the HVA was moderately positive $(r=0.6133)$. The correlation between IMA and MAA was very weakly positive $(r=0.1082)$, while the correlation between IMA and MADA was moderately positive $(r=0.5913)$.

\section{DISCUSSION}

Many angles on dorsoplantar radiographs of the foot have been employed in the study of hallux valgus. ${ }^{17}$ However, most have not been useful for the determination of the absolute positions and relationships of the bones. One focus of discussion has been the point of origin of metatarsus primus varus. ${ }^{17-19}$ Some studies have found the mean angle of metatarsus primus varus was larger in the patients who had hallux valgus. However, because this angle includes not only the varus angulation of the first metatarsal, but also the valgus angulation of the first cuneiform. ${ }^{20,21}$ It is possible that the first cuneiform is in valgus, but there is also a possibility that the entire forefoot is in adduction. In an anatomical study, Haines and McDougall ${ }^{22}$ noted that the distal articular surface of the first cuneiform inclined medially in hallux valgus.

Correlation of the clinical deformity, angular measurement, and surgical planning is a contentious issue in hallux valgus surgery. There is good evidence to suggest that varus positioning of the first metatarsal predisposes a hallux valgus deformity. But the quantification of primus metatarsus varus remains far from perfect. The new angle 


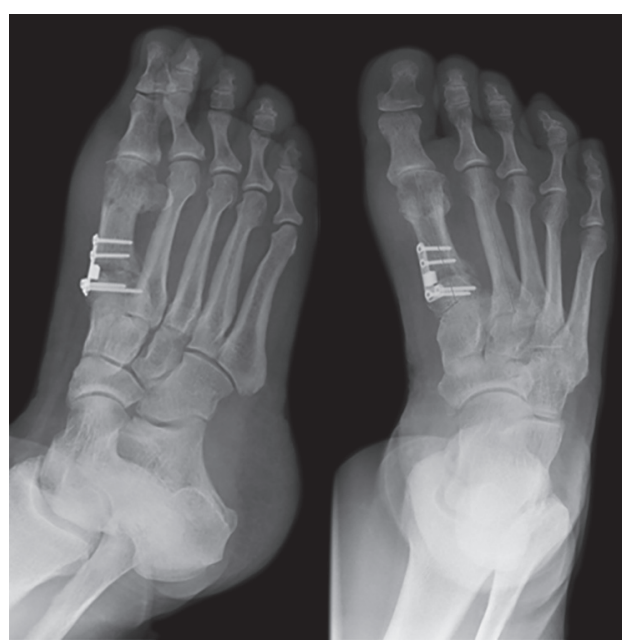

Fig. 3: First metatarsal basal osteotomy as a remedy for MADA $>30^{\circ}$

that we describe seems to bridge this gap. In cases where the first metatarsal is in varus despite having a normal IMA, a distal or shaft osteotomy may not provide with adequate correction. In such circumstances, we recommend use of proximal metatarsal osteotomy to achieve better correction and accurate realignment (Fig. 3).

Our study does have some shortcomings. Firstly, ours is a radiological and inferential study design with little clinical correlation and only 58 radiographs. Secondly, we could have included only patients with metatarsus adductus and hallus valgus to better compare the effect of forefoot axis deviation. This would have given a greater statistical validity to the correlation assessment.

\section{CONCLUSION}

The MADA is a measurement that comprehensively indicates the spatial position of first metatarsal in relation to the forefoot axis and quantifies its varus positioning. Of the radiographic measurements available to quantify hallux valgus severity, the MADA had the best correlation in our study. A MADA of $30^{\circ}$ or more should be considered abnormal. This reflects the amount of metatarsus varus more effectively than the IMA. It also showed the hallux valgus severity better than the IMA. Both the associations between IMA and HVA and between MADA and HVA were statistically significant $(p<0.05)$. We recommend routine use of the MADA to plan hallux valgus osteotomy. A MADA of more than 30 degrees requires re-alignment of the first metatarsal shaft from its varus position. This was achieved by the metatarsal basal osteotomy in our series.

\section{REFERENCES}

1. Kelikian, H. Hallux valgus, allied deformities of the forefoot and metatarsalgia. Philadelphia (PA): WB Saunders; 1965. p. 1-5.
2. Mann, RA.;Coughlin,MJ. Adulthalluxvalgus. In:CoughlinMJ, Mann RA, editors. Surgery of the foot and ankle. 7th ed. St Louis (MO): Mosby; 1999. p. 150-269.

3. Trnka HJ, Muhlbauer M, Zembsch A, Hungerford M, Ritschi P, Salzer M. Basal closing wedge osteotomy for correction of hallux valgus and metatarsus primus varus: 10 to 22 years follow up. Foot Ankle Int 1999 Mar;20(3):171-177.

4. Dereymaeker G. Scarf osteotomy for correction of hallux valgus surgical technique and results as compared to distal chevron osteotomy. Foot Ankle Clin 2000 Sep;5(3):513-524.

5. Kramer J, Barry LD, Helfman DN, Mehnert JA, Pokrifcak VM. The modified scarf bunionectomy. J Foot Surg 1992 JulAug;31(4):360-367.

6. Austin DW, Leventen EO. A new osteotomy for hallux valgus: a horizontally directed "V" displacement osteotomy of the metatarsal head for hallux valgus and primus varus. Clin Orthop Relat Res 1981 Jun;157:25-30.

7. Robinson AH, Limbers JP. Modern concepts in the treatment of hallux valgus. J Bone Joint Surg (Br) 2005 Jul;87(8): 1038-1045.

8. Mann RA. Decision-making in bunion surgery. Instr Course Lect 1990;39:3-13.

9. Mann RA, Coughlin MJ. Hallux valgus etiology, anatomy, treatment and surgical considerations. Clin Orthop Relat Res 1981 Jun;157:31-41.

10. Faber FW, Mulder PG, Verhaar JA. Role of first ray hypermobility in the outcome of the Hohmann and the Lapidus procedure. A prospective, randomized trial involving one hundred and one feet. J Bone Joint Surg Am 2004 Mar; 86-A(3):486-495.

11. Deenik AR, Pilot P, Brandt SE, van Mameren H, Geesink RGT, Draijer WF. Scarf versus chevron osteotomy in hallux valgus: a randomised controlled trial in 96 patients. Foot Ankle Int 2007 May;28(5):537-541.

12. Truslow W. Metatarsus primus varus or hallux valgus. J Bone Joint Surg 1925 Jan;7:98-108.

13. Hardy RH, Clapham JC. Observations on hallux valgus: based on a controlled series. J Bone Joint Surg Br 1951 Aug; 33-B(3):376-391.

14. Lundberg BJ, Sulja T. Skeletal parameters in the hallux valgus foot. Arch Orthop Scand 1972 Aug;43(6):576-582.

15. Piggot $\mathrm{H}$. The natural history of hallux valgus in adolescence and early adult life. J Bone Joint Surg (Br) 1960 Nov; 42-B:749-760.

16. Engel E, Erlick N, Krems I. A simplified metatarsus adductus angle. J Am Podiatry Assoc 1983 Dec;73(12):620-628.

17. Antrobus JN. The primary deformity in hallux valgus and metatarsus primus varus. Clin Orthop Relat Res 1984 Apr;184:251-255.

18. Houghton GR, Dickson RA. Hallux valgus in the younger patient: the structural abnormality. J Bone Joint Surg 1979 May;61-B(2):176-177.

19. Scott G, Wilson DW, Bentley G. Roentgenographic assessment in hallux valgus. Clin Orthop Relat Res 1991 Jun;267:143-147.

20. Tanaka Y, Takakura Y, Kumai T, Samoto N, Tamai S. Radiographic analysis of hallux valgus. A two-dimensional coordinate system. J Bone Joint Surg Am 1995 Feb;77(2):205-213.

21. Smith RW, Reynolds JC, Stewart MJ. Hallux valgus assessment: report of research committee of American Orthopaedic Foot and Ankle Society. Foot Ankle 1984 Sep-Oct;5(2):92-103.

22. Haines RW, McDougall A. The anatomy of hallux valgus. J Bone Joint Surg Br 1954 May;36-B(2):272-293. 